\title{
CHANGES IN THE CHARACTERISTIC IMPEDANCE OF TEXTILE SIGNAL LINES WHILE MECHANICALLY LOADED
}

\author{
Jacek Leśnikowski, Paweł Kubiak \\ Department of Architecture of Textiles, Lodz University of Technology, Żeromskiego 116, 90-924 Łódź, Poland \\ E-mail: pawel.kubiak@edu.p.lodz.pl; lesnik@p.lodz.pl
}

\begin{abstract}
:
The paper presents studies over the changes in the characteristic impedance of selected type of textile signal lines (TSLs) during mechanical loads. The article describes the construction of tested lines, the measurement method, and statistical analysis of the collected results.
\end{abstract}

\section{Keywords:}

textile signal lines, TSLs, textile transmission lines, TTLs, characteristic impedance, mechanical properties of textiles, electrical properties of textiles, smart garment

\section{Introduction}

Textile signal lines (TSLs) are a modern alternative to conventional lines that use conventional wires for data transmission. When constructing such lines, textile materials are used to allow easy application in ergonomic wearable textile products. These lines should have the best signal transmission parameters that ensure proper transmission of broadband and high-frequency signals. TSLs can be used in a wide range of potential applications, e.g., for transferring digital data between electronic systems implemented in modern garments or smart textiles. Potential applications of such elements are fine for a wide variety of smart textiles with a monitoring system of physiological parameters of athletes [1], the elderly, or chronically ill people [2] as well as newborns [3]. Other application possibilities could be useful in wearable clothing for monitoring threats dedicated to workers such as soldiers, firemen, and miners who are exposed to harmful working conditions [4-5]. In these systems, it is often crucial to transmit digital signals characterized by a wide frequency spectrum without any losses. Another potential area of application for this type of lines is power lines for textile antennas [69]. Other examples of applications of transmission lines and electroconductive elements are described in Ref. [10].The mentioned example areas of TSL applications show that these lines should be able to transmit accurate broadband signals and resistant to the environmental conditions as well as for the stresses and strains which could be generated in textiles. One of the basic values characterizing the ability of TSL to correctly transmit broadband signals is its characteristic impedance.

For lossless line, the characteristic impedance is expressed by the following equation:

$$
Z_{c}=\sqrt{\frac{L}{C}}
$$

where $L$ is the unit inductance of the line and $C$ is the unit capacity of the line.
In the real signal line, there are losses on the serial resistance of conductive elements as well as losses caused by the existence of the conductance $G$ of the line's substrate. The characteristic impedance of such a line can be expressed as:

$$
Z_{c}=\sqrt{\frac{R+\mathrm{j} \omega L}{G+\mathrm{j} \omega C}},
$$

where $R$ is the serial unit resistance of electroconductive part of the line, $G$ is the unit conductance of the dielectric substrate of the line, and $w$ is the pulsation.

The value of this impedance, and in particular its distribution along the length of the line, has a clear influence on the fit of the elements of the transmission system in the electronic system consisting of a transmitter, line, and receiver [11]. The quality of the abovementioned match defines the ability of the line to send the signal without losses, distortion, and other unwanted interferences and with maximum efficiency.

Because of the wide range of potential applications of TSLs, the work on them is nowadays carried out by many researchers [12-17]. These conditions can cause, for example, mechanical deformation, changes in the properties of the line under the influence of temperature and humidity, or the presence of human sweat. These are very important issues, because such lines should work properly not only on the laboratory condition but also in wearable textiles used regularly. The following sections present research on the resistance of a selected type of TSLs to mechanical deformations that may occur during their use in modern clothing (smart garment).

\section{The object of research and measuring system}

The subject of the research was a set of 20 TSLs. These lines were made using the method of sewing straps made of electrically conductive fabric to the substrate made from a nonconducting fabric [17]. This sewing method has plenty of advantages compared to other methods of making lines such 
as printing and embroidering. These advantages include the low cost of making a line, the possibility of making such line by the conventional sewing equipment, and sewing machine. In the tested set of lines, the substrate was made of fabrics of various thicknesses, different weave, and surface weight. Table 1 summarizes four examples of fabrics from which substrates of the tested lines were made, characterized by the smallest and largest values of thickness and surface area. The tested lines consist of a signal path sewn to the upper part of the fabric forming the substrate of the line and two mass paths sewn to the bottom of the fabric. The arrangement of the conductive paths and their stitches to the substrate are shown in Figure $1 a$ and $b$. The signal path and mass paths were made of an electroconductive fabric called sponge produced by Soliani [18]. The basic parameters of this fabric are summarized in Table 2. All electroconductive paths had the same width of $5 \mathrm{~mm}$. All tested signal lines were $30 \mathrm{~cm}$ long and $2.5 \mathrm{~cm}$ wide. When sewing the line, the distance between the mass paths was chosen so that the line had a characteristic impedance close to $50 \mathrm{Ohms}$ to match the impedance to the impedance of the measuring system. These lines during the measurement were put in a specially designed clamp as shown in Figure 2.

These jaws prevent the line from sliding out of the electrical clamp under the longitudinal force stretching the line during the measurements. The ends of electroconductive tracks are fixed in electrical terminals ended with standard SMA-type connector. This connection, in turn, makes it possible to connect a line to the measuring apparatus.

\section{Measurement method of the TSL characteristic impedance}

The block diagram of the measuring instrument is shown in Figure 3 . The measurements of the characteristic impedance were made using Tektronix Digital Serial Analyzer DSA8200. The analyzer was equipped with an 80A02 ESD Protection Module and 80E08 TDR/Sampling Module with an input impedance of 50 Ohms, which indicates the overall measurement system impedance.

The results were collected using the Serial X-Press extension software installed in the DSA8200 Analyzer. The method of characteristic impedance measurements by the TDR method has been widely described in the literature $[19,20]$.

All measurements were made in a normal climate: at $20^{\circ} \mathrm{C}$ and air humidity equal to $65 \%$ according to the standard [21].

The impedance profile of each line connected to the measurement terminal (Figure 2) was measured. The measured line was placed vertically, and the other end of line was unloaded, its self-mass only, loaded with a mass of $\mathrm{m} 1=$ $0.414 \mathrm{~kg}$, loaded with a mass of $\mathrm{m} 2=\mathrm{m} 1+1.047 \mathrm{~kg}$.

In each of these cases, five measurements of the impedance profile of each of the tested lines were made. Then, the average profile was determined from five profiles. The abovementioned measurements were made for each of the 20 tested lines.

\section{Results and statistical analysis}

As a result, the characteristic impedance profiles of the 20 TSLs were obtained. This profile shows the value of the characteristic impedance of each line as a function of the distance from the beginning of the line. From the profile, we can see the value of the characteristic impedance at any point of the line. An exemplary average profile of the characteristic impedance of a TSL, for three cases of its loading, is shown

Table 1. Example of selected materials used as substrate of TSLS

\begin{tabular}{|c|c|c|c|c|c|c|}
\hline Line no. & Weave & $\begin{array}{c}\text { Thickness } \\
(\mathbf{m m})\end{array}$ & $\begin{array}{c}\text { Surface mass } \\
\mathbf{( g / \mathbf { m } ^ { 2 } )}\end{array}$ & $\begin{array}{c}\text { Warp yarn } \\
\text { density } \\
\text { (threads/cm) }\end{array}$ & $\begin{array}{c}\text { Weft yarn } \\
\text { density } \\
\text { (threads/cm) }\end{array}$ & Remarks \\
\hline 1 & Plain & 0.27 & 170 & 42 & 29 & $\begin{array}{c}\text { The smallest } \\
\text { thickness }\end{array}$ \\
\hline 2 & Plain & 0.80 & 230 & 22 & 18 & $\begin{array}{c}\text { The largest } \\
\text { thickness }\end{array}$ \\
\hline 3 & Plain & 0.38 & 89 & 25 & 21 & $\begin{array}{c}\text { The smallest } \\
\text { surface area }\end{array}$ \\
\hline 4 & Twill & 0.56 & 290 & 40 & 24 & $\begin{array}{c}\text { The largest } \\
\text { surface mass }\end{array}$ \\
\hline
\end{tabular}

TSLs, textile signal lines.

Table 2. Basic parameters of metalized fabric used as electroconductive paths of the line

\begin{tabular}{|c|c|c|c|c|c|c|c|}
\hline Stuff & $\begin{array}{l}\text { Thickness } \\
\text { (mm) }\end{array}$ & $\begin{array}{l}\text { Surface } \\
\text { resistivity } \\
\text { (Ohm/sq) }\end{array}$ & $\begin{array}{c}\text { Nickel } \\
\text { amount } \\
\left(\mathrm{g} / \mathrm{m}^{2}\right)\end{array}$ & $\begin{array}{l}\text { Total weight } \\
\left(\mathrm{g} / \mathrm{m}^{2}\right)\end{array}$ & Weave & $\begin{array}{c}\text { Warp } \\
\text { density } \\
\text { (yarns/dm) }\end{array}$ & $\begin{array}{l}\text { Weft density } \\
\text { (yarns/dm) }\end{array}$ \\
\hline $\begin{array}{c}\text { Nickel } \\
\text { metallized } \\
\text { polvester }\end{array}$ & 0.15 & $\begin{array}{c}\text { Maximum } \\
\text { average, } 0.4\end{array}$ & 16 & $60 \pm 15$ & Plain & 260 & 180 \\
\hline
\end{tabular}

The TSL holding elements in the clamp are made in the form of semicircular jaws made of dielectric material. 
a

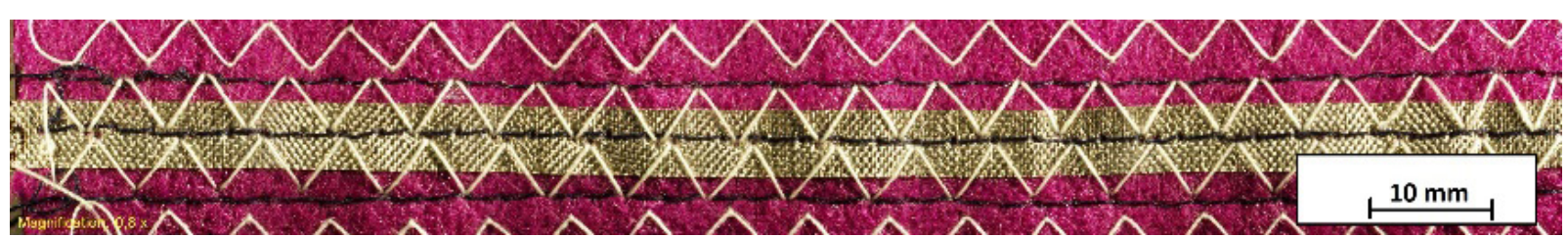

b

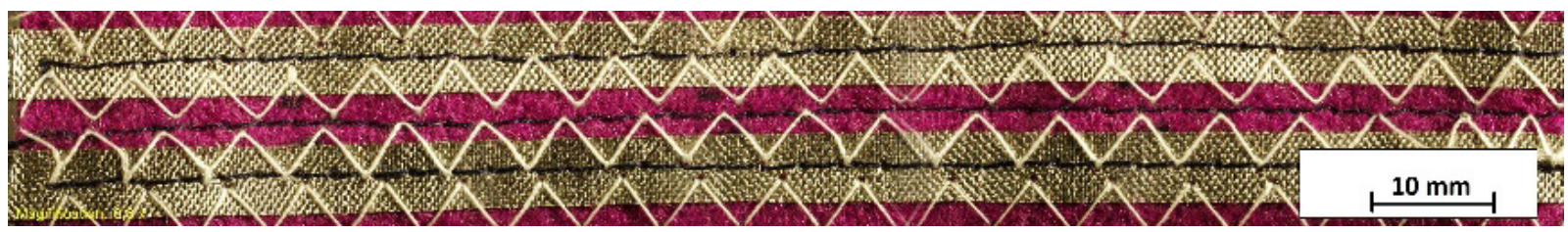

Figure 1. Example of the construction of the line being the object of research: a) view from the signal path side, b) view from the path of the mass side [11]

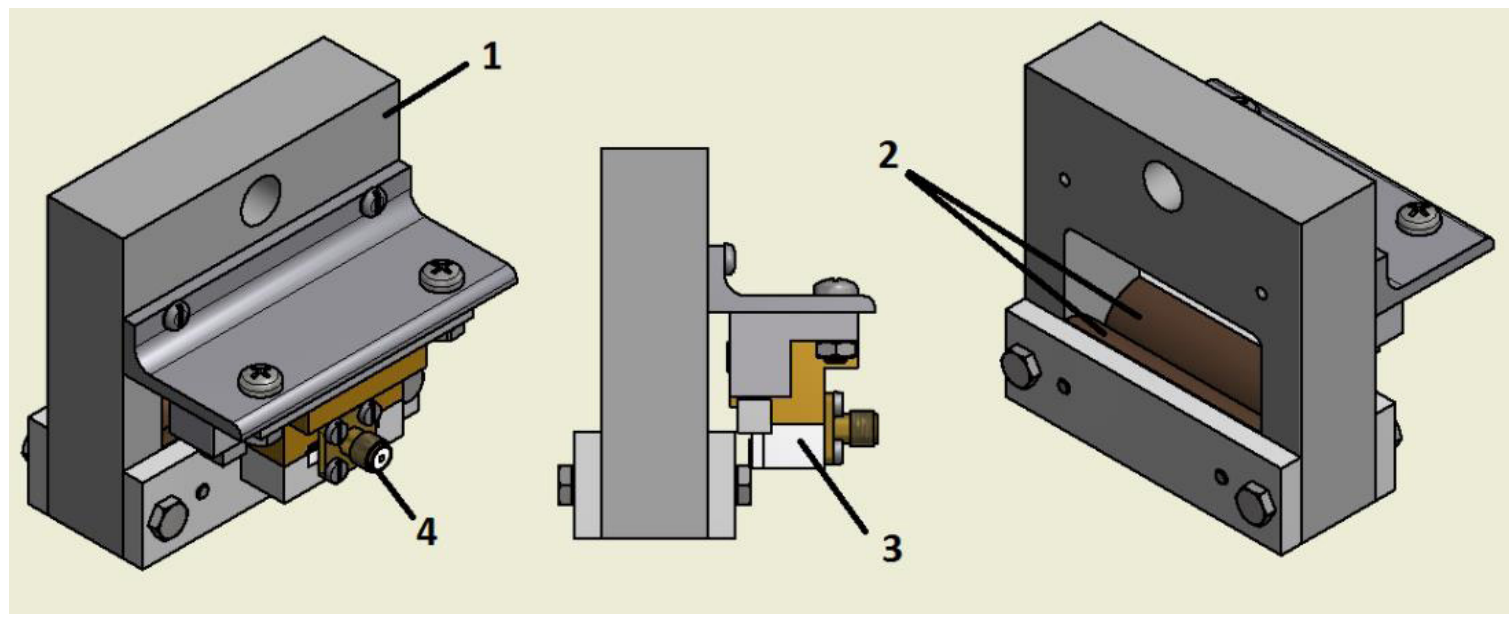

Figure 2. The clamp designed and made for testing the signal lines (1, clamp body; 2 , nonconductive jaws; 3 , electric terminal; 4, SMA connector)

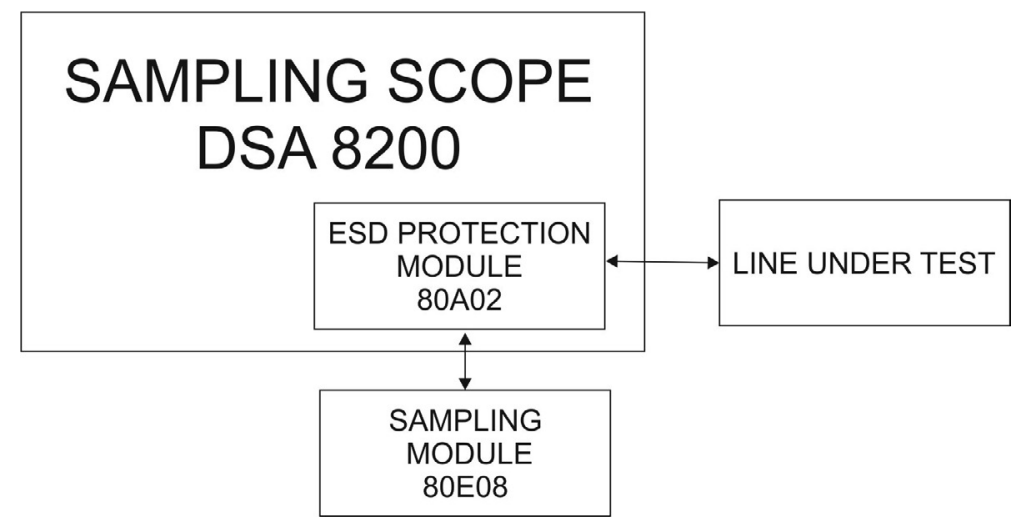

Figure 3. Block diagram of the measuring instrument

in Figure 4.

The quality of the transmission line can be easily evaluated from the impedance profile (the ideal TSL line should have a constant impedance value along its entire length). Next, the statistical analysis was performed. The analysis was made to check which of the selected parameters characterizing the substrate of the line could affect the value of its characteristic impedance under the mechanical load. The influence of the thickness, surface mass, and weave of the fabric from which the substrate of the line was made was analyzed.

In order to perform the analysis, the set of all examined lines was divided into three subsets. In each subset, there were lines whose values of the analyzed feature (thickness, surface mass) were in the range assigned to each subset. All tested 


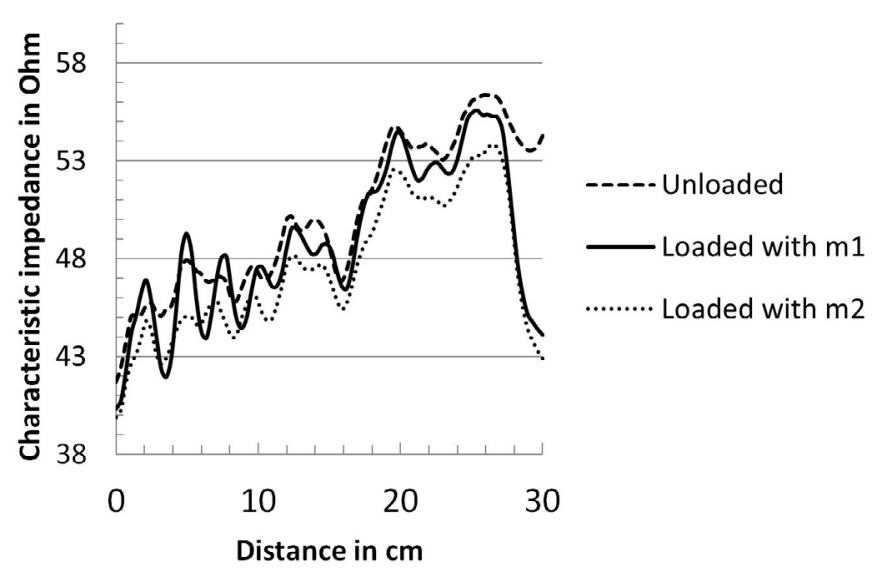

Figure 4. Profile of the characteristic impedance of the line 2 (see Table 1 for line details)

TSLs were therefore grouped into three subsets depending on the thickness of their substrate, surface mass of the line, and the weave of material used on the substrate of the given line. The method of grouping the lines is summarized in Table 3. The selection of group compartments was a subjective matter, and the division was made so that in each of the three subgroups there were at least five cases of lines categorized in terms of a given feature. The lines were also grouped for a weave of the substrate material, where three weaves were specified: plain, twill, and satin.

For the statistical analysis, the average value from each average impedance profile was determined according to the formula:

$$
Z_{\mathrm{av}}=\frac{\sum_{i=1}^{n} Z_{i}}{n},
$$

where $Z_{a v}$ is the average line impedance, $Z i$ is the line impedance at ith point of average impedance profile, $n$ is the number of points (measurement values) of which the line impedance profile consists of.

A nonparametric Kruskal-Wallis test was used for statistical analysis. Due to the fact that the analyzed parameters of the signal lines were divided into more than two groups, the statistical test had to be able to compare within several independent groups.

In all next tests, the significance level was assumed to be $a=$ 0.05 . First, the zero hypothesis, $\mathrm{HO}$, assumed no impact of the load on the line with the weights of $\mathrm{m} 1$ and $\mathrm{m} 2$ on the value of its characteristic impedance. The values of the characteristic impedance of the line for its various loads are shown in Figure 5. The figure shows that the mean value of the impedance is lower when the force stretching the lines is higher. This was confirmed by the result of the Kruskal-Wallis test based on which the assumed zero hypothesis was rejected (Table 4).

In the analysis, it was checked whether selected parameters of the substrate (surface mass, thickness, weave) affect the changes in the characteristic impedance value of the loaded line. For this purpose, the zero hypothesis $\mathrm{HO}$ was assumed that there was no impact of the tested feature on the value of changes in the characteristic impedance of the line under the load.

The impedance changes as shown in Figures 6-8 and used in statistical tests were determined from the formula:

$$
\Delta Z=Z_{0}-Z_{m_{2}}
$$

where $Z_{0}$ is the mean impedance of the unloaded line and $Z_{\mathrm{m} 2}$ is the average impedance of the line loaded with $\mathrm{m} 2$ mass.

The impedance changes of each TSL are shown in Figure 6 (for lines with substrates made of fabrics of various surface masses, loaded with $\mathrm{m} 2$ mass).

TSL impedance values for lines with different substrate thickness, loaded with $\mathrm{m} 2$, are shown in Figure 7.

All three types of substrate material weave such as plain, twill, and satin were also analyzed.

Changes in the characteristic impedance under the influence of the load of $\mathrm{m} 2$ stretching the lines for three groups of lines characterized by different weave are shown in Figure 8.

A summary list of all statistical tests performed is summarized in Table 4.

\section{Conclusions}

As a result of the tests, it was obtained that due to the tensile force acting along the line, its characteristic impedance decreases. This was confirmed by the nonparametric statistical test (Table 4 ), in accordance with the Kruskal-Wallis test carried out with the assumed significance level of $\alpha=0.05$, the examined properties of the substrate of the line, such as thickness and weave, affect the value changes of the characteristic impedance of the TSLs

Table 3. Separated TSL groups due to the value of surface mass, thickness, and weave

\begin{tabular}{|c|c|c|c|c|c|c|c|}
\hline $\begin{array}{c}\text { Thickness } \\
\text { of the } \\
\text { substrate } \\
\mathbf{( m m})\end{array}$ & $\begin{array}{c}\text { Name of the } \\
\text { group }\end{array}$ & $\begin{array}{c}\text { Amount of } \\
\text { lines }\end{array}$ & $\begin{array}{c}\text { Surface } \\
\text { mass }\left(\mathbf{g} / \mathbf{m}^{2}\right)\end{array}$ & $\begin{array}{c}\text { Name of the } \\
\text { group }\end{array}$ & $\begin{array}{c}\text { Amount of } \\
\text { lines }\end{array}$ & $\begin{array}{c}\text { Weave } \\
\text { lines }\end{array}$ \\
\hline $27-45$ & Thin & 5 & $89-165$ & Lightweight & 8 & Plain & 11 \\
\hline $45-59$ & Medium & 8 & $166-229$ & Medium & 7 & Twill & 5 \\
\hline $60-80$ & Thick & 7 & $230-290$ & Heavy & 5 & Satin \\
\hline
\end{tabular}


during their stretching, in accordance with the Kruskal-Wallis test carried out with the assumed significance level of alpha $=0.05$, the value of the surface mass of the substrate of the line does not affect the value of changes of the characteristic impedance of the line during its stretching.

As a result of the analysis of the test results, it was found that the lines made of fabrics with a satin weave had the smallest impedance change under the influence of the force loading the lines (Figure 8). In turn, the lines with a substrate made of twill

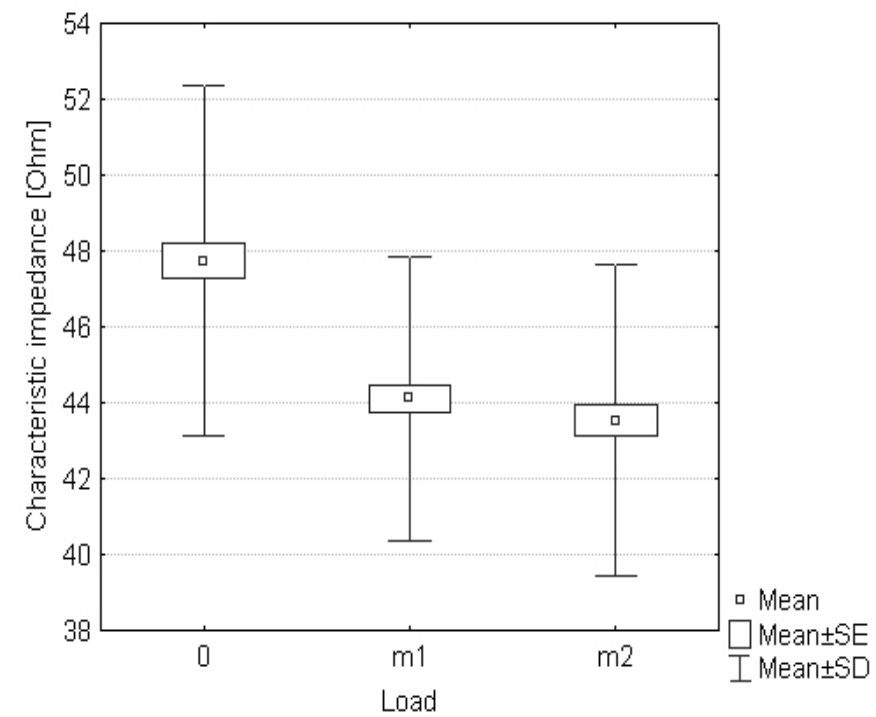

Figure 5. Change in characteristic impedance depending on the load of the tested lines

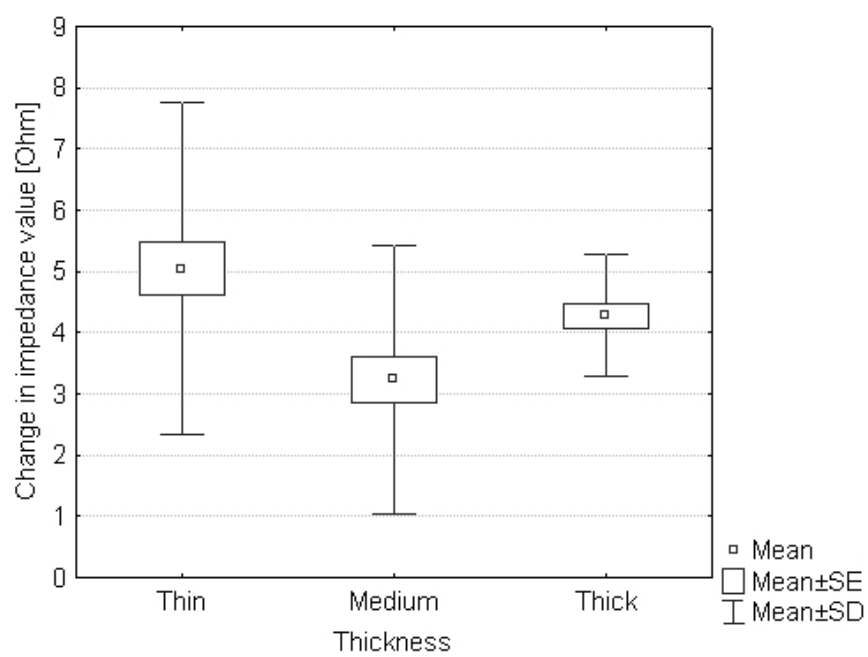

Figure 7. Change in characteristic impedance of lines with different substrate thickness under the influence of load $\mathrm{m} 2$ weave fabrics show the largest impedance changes. It can therefore be assumed that by using a satin fabric on the TLS substrate, a line will be more resistant to tensile forces acting along the line than in the case of twill weave fabrics.

\section{Declaration of conflicting interests}

The authors declared no potential conflicts of interest with respect to the research, authorship, and/or publication of this paper.

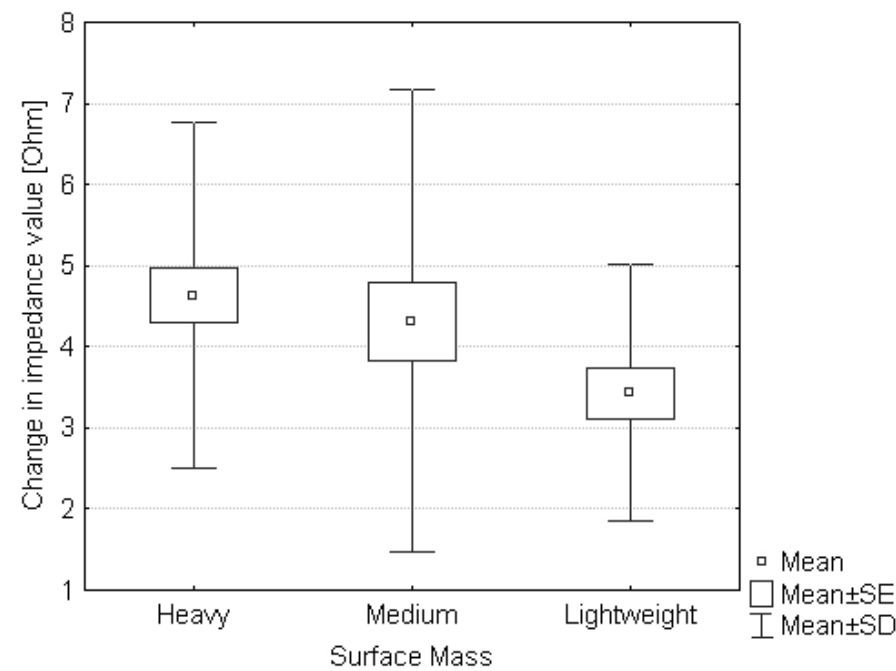

Figure 6. Change in characteristic impedance of lines with different surface masses under the influence of load $\mathrm{m} 2$

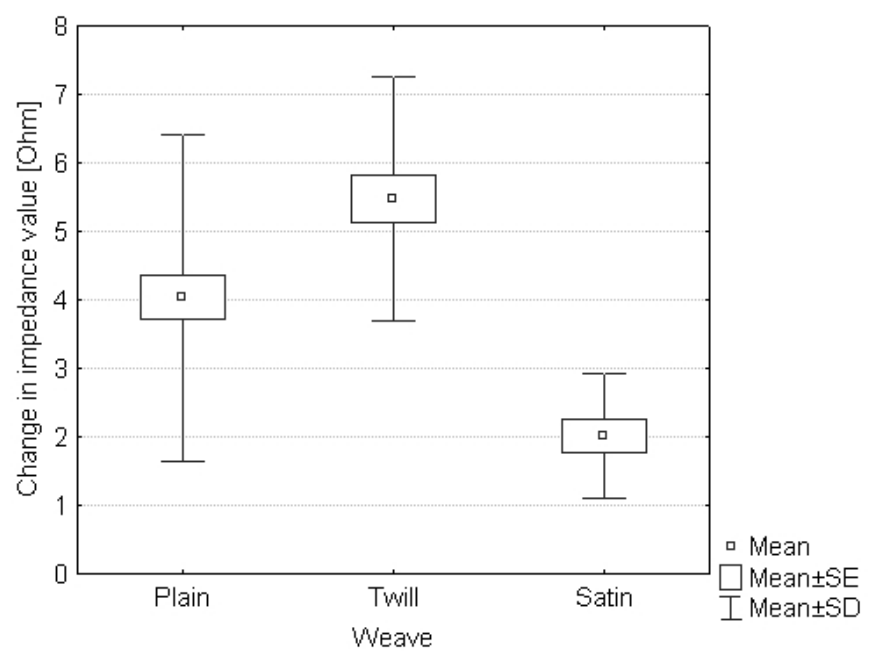

Figure 8. Change in characteristic impedance of lines with different weave of the substrate under the influence of load $\mathrm{m} 2$

Table 4. The results of the Kruskal-Wallis statistical test for the set of 20 TSLs

\begin{tabular}{|c|c|c|}
\hline Tested attribute & Obtained $p$-value & Ho hypothesis \\
\hline Load & $p=0.0007$ & Rejected \\
\hline Surface mass & $p=0.0793$ & Rejected \\
\hline Thickness of substrate & $p=0.0026$ & Rejected \\
\hline Weave of substrate & $p<0.0001$ & \\
\hline
\end{tabular}




\section{References}

[1] Perego, P., Moltani, A., Andreoni, G. (2012). Sport monitoring with smart wearable system. In 9th International Conference on Wearable Micro and Nano Technologies for Personalized Health, 177, 224-228.

[2] Lin, C., Yang, C., Zhou, Z., Wu, S. (2018). Intelligent health monitoring system based on smart clothing. International Journal of Distributed Sensor Networks, 14(8), 1-9.

[3] Zhu, Z., Liu T., Li, G., Li, T., Inoue, Y. (2015). Wearable sensor systems for infants. Sensors, 15, 3721-3749.

[4] Scataglini, S., Andreoni, G., Gallant, J. (2019). Smart clothing design issues in military applications. Advances in Intelligent Systems and Computing, 795, 158-168.

[5] Gniotek, K., Gołębiowski, J., Leśnikowski, J. (2009). Temperature measurements in a textronic fireman suit and visualisation of the results. Fibres and Textiles in Eastern Europe, 72(1), 97-101.

[6] Blecha, T., Linhart, R., Reboun, J. (2014). Screen printed antennas on textile substrate. Proceedings of the 5th Electronics System-integration Technology Conference, 1-4.

[7] Hertleer, C., Tronquo, A., Rogier, F. (2008). The use of textile materials to design wearable microstrip patch antennas. Textile Research Journal, 78(8), 651-658.

[8] Yadav, A., Singh, V. K., Chaudhary, M., Mohan, H. (2015). A review on wearable textile antenna. Journal of Telecommunication, Switching Systems and Networks, 2(3), 37-41.

[9] Lim, E. G., Wang, Z., Wang, J. C., Leach, M. (2014). Wearable textile substrate patch antennas. Engineering Letters, 22(2), 1-8.

[10] Lund, A., van der Velden, N. M., Persson, N. -K., Hamedi, M. M., Müller, C. (2018). Electrically conducting fibres for e-textiles: an open playground for conjugated polymers and carbon nanomaterials. Materials Science and Engineering: $R:$ Reports, 126, 1-29.
[11] Leśnikowski, J. (2013). Badanie właściwości tekstylnej linii transmisyjnej wykonanej metodą naszywania, Przegląd Elektrotechniczny, 3a, 65-68.

[12] Cottet, D., Grzyb, J., Kirstein, T., Troster, G. (2003). Electrical characterization of textile transmission lines. IEEE Transactions on Advanced Packaging, 26(2), 182190.

[13] Chedid, M., Belov, I., Leisner, P. (2007). Experimental analysis and modelling of textile transmission line for wearable applications. International Journal of Clothing Science and Technology, 19(1), 59-71.

[14] Choiinni, J. (2007). Design and evaluation of textile-based signal transmission lines and keypads for smart wear. Human-Computer Interaction, Part II, HCII, LNCS 4551, 1078-1085.

[15] Yang, Y., Cho, G., (2009). Novel stretchable textilebased transmission bands: electrical performance and appearance after abrasion/laundering, and wearability. Human-Computer Interaction, Part III, Springer-Verlag Berlin Heidelberg, 806-813.

[16] Leśnikowski, J. (2011). Textile transmission lines in the modern textronic clothes. Fibres \& Textiles in Eastern Europe, 19(6), 89-93.

[17] Leśnikowski, J. (2015). New kind of textile transmission line with an impedance of 50 ohms. Fibres \& Textiles in Eastern Europe, 23, 2(110), 51-54.

[18] http://www.solianiemc.com/products/shielding-conductivetextile-fabrics/emc-emi-nickel-polyester-fabrics/, (2018). Retrieved: 12,03,2018.

[19] TDR Techniques for Characterization Techniques for Characterization and Modeling of Electronic Packaging and Modeling of Electronic Packaging, 2001, TDA Systems Inc.

[20] Time Domain Reflectometry Theory Application Note 1304-2, Agilent Technologies, May 10, 2006.

[21] Standard: ISO 139:2005. Textiles - Standard atmospheres for conditioning and testing. 